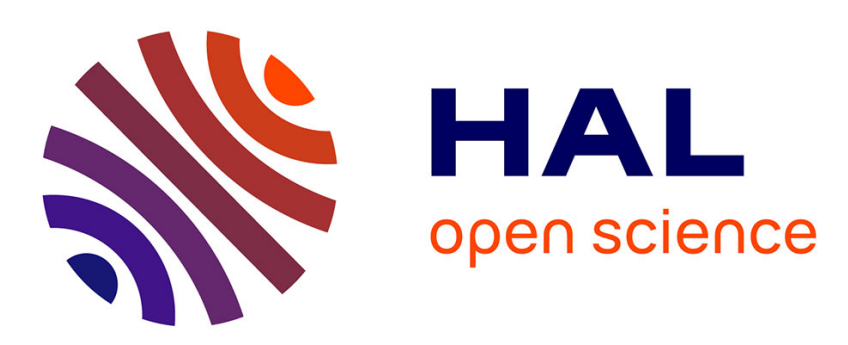

\title{
Temperature-dependent phase evolution of copper-oxide thin-films on $\mathrm{Au}(111)$
}

Christoph Möller, Hanna Fedderwitz, Claudine Noguera, Jacek Goniakowski, Niklas Nilius

\section{> To cite this version:}

Christoph Möller, Hanna Fedderwitz, Claudine Noguera, Jacek Goniakowski, Niklas Nilius. Temperature-dependent phase evolution of copper-oxide thin-films on $\mathrm{Au}(111)$. Physical Chemistry Chemical Physics, 2018, 20 (8), pp.5636 - 5643. 10.1039/C7CP08387D . hal-01911233

\section{HAL Id: hal-01911233 https://hal.sorbonne-universite.fr/hal-01911233}

Submitted on 7 Jul 2020

HAL is a multi-disciplinary open access archive for the deposit and dissemination of scientific research documents, whether they are published or not. The documents may come from teaching and research institutions in France or abroad, or from public or private research centers.
L'archive ouverte pluridisciplinaire HAL, est destinée au dépôt et à la diffusion de documents scientifiques de niveau recherche, publiés ou non, émanant des établissements d'enseignement et de recherche français ou étrangers, des laboratoires publics ou privés. 
Received 14th December 2017. Accepted 1st February 2018

DOI: $10.1039 / c 7 c p 08387 d$

\title{
Temperature-dependent phase evolution of copper-oxide thin-films on $\mathrm{Au}(111) \dagger$
}

\author{
Christoph Mo"ller, ${ }^{a}$ Hanna Fedderwitz, ${ }^{a}$ Claudine Noguera, ${ }^{\text {bc }}$ Jacek \\ Goniakowski $^{\star b c}$ and Niklas Nilius ${ }^{\star a}$
}

\begin{abstract}
The formation of ultrathin copper oxide layers on an $\mathrm{Au}(111)$ surface is explored with scanning tunneling microscopy and density functional theory. Depending on the thermal treatment of as-grown $\mathrm{Cu}-\mathrm{O}$ samples, a variety of thin-film morphologies is observed. Whereas $1 \mathrm{D}$ oxide stripes with $\mathrm{Au}[11 \% 2]$ and $\mathrm{Au}[1 \% 10]$ orientation emerge at 450 and $550 \mathrm{~K}$ annealing, respectively, a planar $(2 \quad 2) \mathrm{Cu}-\mathrm{O}$ network with specific domain structure develops at higher temperature. The latter is ascribed to a $\mathrm{Cu}_{3} \mathrm{O}_{2}$ honeycomb lattice with oxygen ions alternatingly located in surface and interface positions. Strain minimization and a thermodynamic preference for Cu-rich edges lead to the formation of structurally well-defined boundaries, delimiting either triangular, elongated or stripe-like $\mathrm{Cu}_{3} \mathrm{O}_{2}$ domains. The low-temperature phases compirse complex arrangements of hexagonal and square $\mathrm{Cu}-\mathrm{O}$ units, similar to those found in $\mathrm{Cu}_{2} \mathrm{O}(111)$ and (100) surfaces, respectively. The transitions between different thin-film phases are driven by $\mathrm{Cu}$ dissolution in the gold crystal and $\mathrm{O}_{2}$ evaporation and therefore accompanied by a thinning of the oxide layer with increasing temperature.
\end{abstract}

\section{Introduction}

Ultrathin oxide films on metal supports have developed into versatile model systems to study metal-oxide interfaces with atomic precision and in absence of spurious charging effects common to insulating bulk materials. ${ }^{1-3}$ Over the years, dozens of metal-oxide combinations, mimicking various technologically relevant binary oxides, have been established, most of them with excellent structural properties and homogeneity. While some of them have scalable thicknesses and can be used to study the transition from monolayers to bulk oxides, others exist only in substrate-specific thin-film configurations. Oxide films with scalable thickness are, for instance, $\mathrm{MgO} / \mathrm{Ag}(001)$ and $\mathrm{CaO} / \mathrm{Mo}(001),{ }^{4,5}$ while films with non-bulk stoichiometry, e.g. $\mathrm{Pd}_{4} \mathrm{O}_{5} / \mathrm{Pd}(111)$, $\mathrm{Al}_{10} \mathrm{O}_{13} / \mathrm{NiAl}(110), \mathrm{Si}_{2} \mathrm{O}_{5} / \mathrm{Mo}(112)$ and $\mathrm{FeO}_{2} / \mathrm{Pt}(111)$ only appear as ultrathin wetting layers. ${ }^{6-9}$

The question whether an ad-oxide grows in the form of a thin-film phase or adapts a bulk-like structure right from the beginning depends on various factors. Hereby, the interfacial lattice match plays a major role, as it decides how easy the ad-layer reaches registry with the support and whether

\footnotetext{
${ }^{a}$ Carl von Ossietzky Universität Oldenburg, Institut für Physik, Oldenburg D-26111, Germany.E-mail: niklas.nilius@uni-oldenburg.de

${ }^{b}$ CNRS, Institut des Nanosciences de Paris, UMR 7588, Paris F-75005, France. E-mail: jacek.goniakowski@insp.jussieu.fr

${ }^{c}$ Sorbonne Université, Institut des Nanosciences de Paris, UMR 7588, Paris F-75005, France

$\dagger$ Electronic supplementary information (ESI) available. See DOI: 10.1039/c7cp08387d
}

conventional means of strain relaxation, e.g. the insertion of dislocation lines, are sufficient to adjust the bulk structure. ${ }^{10}$ Of similar importance is the structural and chemical flexibility of the oxide film. ${ }^{11}$ Systems that naturally occur in different compositions, oxidation states and metal-oxygen bonding arrangements show a higher tendency to develop specific thin film phases. The plethora of thin-film titanium-, vanadium-, cobalt- and manganese-oxides grown on either $\mathrm{Au}(111), \mathrm{Rh}(111)$, $\operatorname{Pd}(111)$ or $\operatorname{Ir}(100)$ are good examples in this regard. ${ }^{12-15}$ Oxides with rigid crystal structure and limited chemical flexibility, such as $\mathrm{MgO}$ and $\mathrm{CaO}$, show the opposite behaviour. ${ }^{4,5,16}$ These systems tend to develop bulk-derived structures already as thin films, and overcome registry problems either by dislocation networks or incommensurate interface structures. ${ }^{17,18}$ Finally, the effects of lattice softening, interfacial charge transfer and substrate relaxation need to be considered to rationalize the structural diversity observed in ultrathin oxide films.

The present work deals with the structural and compositional variability of ultrathin copper oxide films grown on the $\mathrm{Au}(111)$ surface. Copper oxides can be found in three bulk phases with deviating $\mathrm{Cu}-\mathrm{O}$ bond lengths and angles, namely $\mathrm{Cu}_{2} \mathrm{O}, \mathrm{Cu}_{4} \mathrm{O}_{3}$ and $\mathrm{CuO} .{ }^{19}$ Especially, cuprous oxide $\left(\mathrm{Cu}_{2} \mathrm{O}\right)$ is of high technological relevance due to its outstanding electronic, optical and chemical properties, e.g. its intrinsic p-type conductance behaviour, a band gap in the visible range and exceptionally large exciton-binding energies. It is therefore a promising material for photocatalytic water splitting and fabrication of all-oxide electronic devices. ${ }^{20}$ Given the large number of $\mathrm{Cu}-\mathrm{O}$ bulk 
structures, the occurrence of various thin-film phases can be anticipated. ${ }^{21}$ Already known are the native $\mathrm{Cu}-\mathrm{O}$ films, prepared by anodic $\mathrm{Cu}$ oxidation in aqueous and alkaline solutions, ${ }^{22,23}$ or by $\mathrm{Cu}(111)$ exposure to gaseous $\mathrm{O}_{2} \cdot{ }^{24}$ The latter comprise highly strained $\mathrm{Cu}-\mathrm{O}$ bilayers with non-bulk stoichiometry and large unit cells, the so called '29' and '44' reconstructions. ${ }^{25}$ Other $\mathrm{Cu}-\mathrm{O}$ binding motifs that are specific to thin films have been identified by density functional theory (DFT) calculations. ${ }^{26,27}$

In recent experiments, we have used the $\mathrm{Au}(111)$ surface for copper-oxide growth, as it features a rather small lattice mismatch of $4.4 \%$ only. ${ }^{28,29}$ Indeed, (111)-oriented $\mathrm{Cu}_{2} \mathrm{O}$ films of high structural quality could be grown over a wide range of preparation conditions. Here, we concentrate on alternative oxide polymorphs, such as $\mathrm{Au}[1 \overline{1} 0]$ and [112]]-oriented $\mathrm{Cu}-\mathrm{O}$ stripes as well as $(2 \times 2) \mathrm{Cu}-\mathrm{O}$ networks, emerging at different growth temperatures and oxygen pressures. The morphology of these films is determined with high-resolution scanning tunnelling microscopy (STM), while their internal structure and thermodynamic stability are analysed with state-of-the-art DFT calculations. Our work aims at connecting the rich $\mathrm{Cu}-\mathrm{O}$ phase diagram to specific properties of this thin-film system, such as a high structural and chemical flexibility of the $\mathrm{Cu}-\mathrm{O}$ network, the role of interface coupling to the gold and the high reducibility of $\mathrm{Cu}$-oxides in vacuum.

\section{Experiment and theory}

The experiments have been performed in a custom-built ultrahigh vacuum STM operated at liquid-nitrogen temperature. The oxide films were prepared by $\mathrm{Cu}$ deposition (99.99\% purity) onto a sputtered and annealed $\mathrm{Au}(111)$ single crystal in $5 \times 10^{-6} \mathrm{mbar}$ of oxygen at room temperature. ${ }^{28}$ Deposition rate and initial $\mathrm{Cu}$ thickness were set to $1 \mathrm{ML} \mathrm{min}^{-1}$ and $5 \mathrm{ML}$, respectively, as calibrated with the $\mathrm{Cu} 2 \mathrm{p} / \mathrm{Au} 4 \mathrm{f}$ intensity ratio of a metallic $\mathrm{Cu} / \mathrm{Au}(111)$ reference in X-ray photoelectron spectra. After deposition, the samples were gently annealed in vacuum to promote film ordering. The respective temperatures are given later in the text. Note that film annealing was accompanied by $\mathrm{Cu}$ dissolution in the $\mathrm{Au}(111)$ crystal, and actual thickness values are therefore lower than anticipated from the initial $\mathrm{Cu}$ exposure.

The DFT calculations were carried out with standard GGA (PW91) or hybrid (HSE03) exchange-correlation functionals, ${ }^{30}$ as implemented in VASP. ${ }^{31}$ While the former largely underestimates the $\mathrm{Cu}_{2} \mathrm{O}$ band gap $(0.46 \mathrm{eV})$, the hybrid approach brings a significant improvement $(1.96 \mathrm{eV})$ and better reproduces the experimental value of $2.15 \mathrm{eV} .{ }^{29}$ The interaction between valence electrons and ionic cores was treated with the projector augmented wave method. ${ }^{32}$ By using soft oxygen pseudopotentials, the Kohn-Sham orbitals could be developed on a plane-wave basis set with $270 \mathrm{eV}$ energy cutoff only. The $\mathrm{Au}$-supported $\mathrm{Cu}-\mathrm{O}$ films were modelled with asymmetric slabs separated by at least $10 \AA$ of vacuum. The positions of all oxide ions were allowed to relax until residual forces dropped below
$0.01 \mathrm{eV} \AA^{-1}$, while the in-plane coordinates of the substrate Au atoms were kept fixed. Further details on the computational settings can be found in the ESI. $\dagger$

\section{Experimental results: temperature- dependent morphology of copper oxide films}

We start our discussion by introducing the different $\mathrm{Cu}-\mathrm{O}$ thin films that have been produced in our experiments. In all preparations, similar values for $\mathrm{Cu}$ coverage and oxidation pressure were used, keeping the post-annealing temperature as sole variable in the series. Fig. 1 depicts the evolution of the film morphology upon increasing the annealing temperature from 450 to $700 \mathrm{~K}$. Even harsher annealing destroys the oxide film, as $\mathrm{Cu}$ partly dissolves in the gold substrate while oxygen desorbs to the gas phase. As a result, the clean Au(111) surface, sometimes exposing the well-known herringbone reconstruction, gets visible again (see ESI $\dagger$ ).

The most softly annealed $\mathrm{Cu}-\mathrm{O}$ films $(T=450 \mathrm{~K})$ are characterized by regular stripe patterns aligned with one of the three $\mathrm{Au}[11 \overline{2}]$ lattice vectors (Fig. 1a). The stripes are made of rectangular unit cells, with the long axis (26-29 A) marking the stripe width and the short one $(10 \AA)$ the periodicity along the stripe. The stripe width corresponds to 9-10 repeat units of the $\mathrm{Au}(111)$ lattice in [110] direction, while the periodicity along the stripe matches two $\mathrm{Au}$ units in the orthogonal [11̄] ] direction. Fig. 2a and b display close-up STM images of $[11 \overline{2}]$-oriented $\mathrm{Cu}-\mathrm{O}$ stripes. Typical structural elements are nearly quadratic building blocks of $5 \times 5 \AA^{2}$ size that appear at different topographic heights and therefore divide the film in bright and dark sub-stripes. The corners of each unit cell

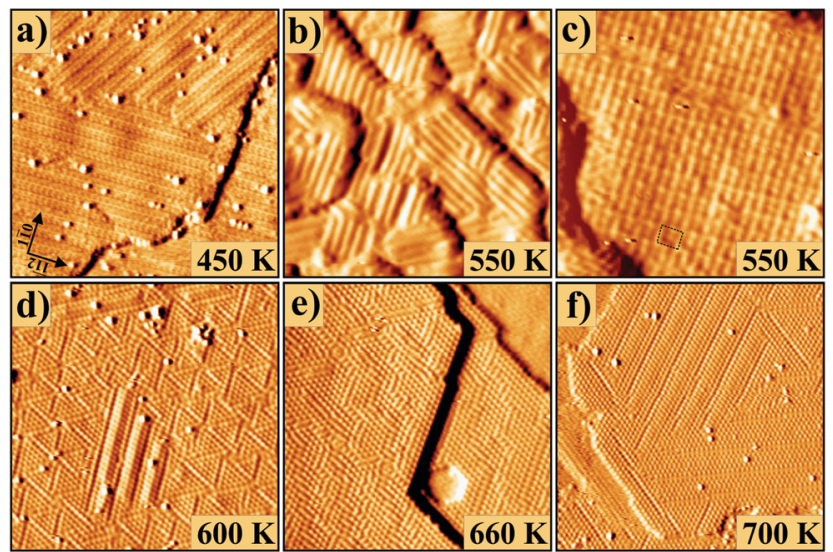

Fig. 1 STM overview images of ultrathin copper oxide films annealed to increasing temperatures $\left(U_{\mathrm{s}}=0.5 \mathrm{~V}, 40 \times 40 \mathrm{~nm}^{2}\right)$ : (a) Au[112] $]$-oriented $\mathrm{Cu}-\mathrm{O}$ stripes, (b) Au[110]-oriented $\mathrm{Cu}-\mathrm{O}$ stripes, $(2 \times 2)$ honeycomb $\mathrm{Cu}-\mathrm{O}$ lattice arranged in (d) triangular domains, (e) elongated domains and (f) $\mathrm{Au}[1 \overline{1} 0]$-oriented stripe domains. The three stripes in the centre of (d) are remnants of the low-temperature phase of (b). Panel (c) shows a minority phase on $550 \mathrm{~K}$ annealed samples that consists of rectangular unit cells $\left(10 \times 10 \mathrm{~nm}^{2}\right)$. 


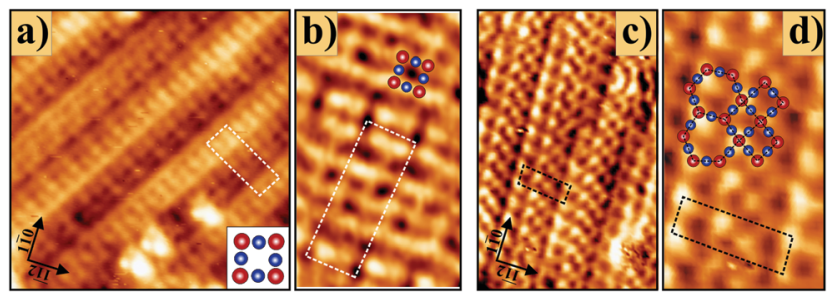

Fig. 2 (a) Overview $\left(10 \times 10 \mathrm{~nm}^{2}\right)$ and (b) high-resolution STM image of [112] $]$-oriented $\mathrm{Cu}-\mathrm{O}$ stripes located on different rotational domains $\left(5 \times 3 \mathrm{~nm}^{2}\right)$. Unit cells are marked with dashed rectangles. The inset shows a quadratic $\mathrm{Cu}_{2} \mathrm{O}$ element as possible building block of the film. (c) Overview $\left(10 \times 10 \mathrm{~nm}^{2}\right)$ and (d) close-up image of [110]-oriented $\mathrm{Cu}-\mathrm{O}$ stripes $\left(4 \times 2.5 \mathrm{~nm}^{2}\right)$ with a tentative ball model combining hexagonal and square motifs. Copper and oxygen atoms are depicted in blue and red, respectively.

are marked by holes, imprinting a comb-like appearance to the stripes.

After annealing to $550 \mathrm{~K}$, the $\mathrm{Cu}-\mathrm{O}$ stripes change orientation and typical structural elements now align with the $\mathrm{Au}[1 \overline{1} 0]$ lattice vectors (Fig. 1b). The new registry with the $\mathrm{Au}(111)$ surface gets reflected in a new oxide unit cell. While the stripe width varies from 15 to $25 \AA$, i.e. in multiples of $\mathrm{Au}[11 \overline{2}]$ lattice vectors, the periodicity along the stripes is fixed to two $\mathrm{Au}[1 \overline{1} 0]$ units or $5.8 \AA$ A The interior of [110] stripes features differently sized pores with regular spacing along the axis but different local arrangements on both sides of the stripes (Fig. 2c and d). Closer inspection reveals both, hexagonal and right-angled structural elements that produce distinct zig-zag lines along the stripe axis. Coexisting with the [110]-oriented $\mathrm{Cu}-\mathrm{O}$ stripes, a 2D pattern made of rectangular $10.0 \times 8.7 \AA^{2}$ cells can be found as minority termination of samples annealed to $550 \mathrm{~K}$ (Fig. 1c).

Further annealing to $600 \mathrm{~K}$ establishes a new registry between $\mathrm{Cu}-\mathrm{O}$ layer and $\mathrm{Au}(111)$ support. The morphology is now determined by a hexagonal pattern with $5.8 \AA$ periodicity, being compatible with a $(2 \times 2)$ superstructure with respect to nonreconstructed $\mathrm{Au}(111)$ (Fig. 1d-f). While the thickness of lowtemperature films discussed so far may exceed $10 \AA$, as concluded from holes in the oxide layer, the $(2 \times 2)$ derived patterns are of monolayer height (see ESI $\dagger$ ). Annealing to temperatures beyond $550 \mathrm{~K}$ is therefore accompanied by a thinning of the $\mathrm{Cu}-\mathrm{O}$ films, whereby excess copper dissolves in the gold crystal. The reduction of film thickness can directly be seen in Fig. 1d, which shows a couple of residual [110] stripes surrounded by the $(2 \times 2)$ monolayer network. The monolayer films seem to have enhanced stability, as they disappear from the $\mathrm{Au}(111)$ surface only at temperatures above $700 \mathrm{~K}$.

While the $(2 \times 2)$ network is characteristic for all hightemperature $\mathrm{Cu}-\mathrm{O}$ phases, the associated domain structure of the film undergoes distinct changes during annealing. In the $600 \mathrm{~K}$ configuration, the domains arrange in triangles of 30-35 A edge length. While their corners meet in single points, their wings share [110]-oriented, low-contrast boundaries (Fig. 1d). With increasing temperature, the $(2 \times 2)$ domains grow in size and evolve from triangular to elongated shapes, now aligning with an $\mathrm{Au}[11 \overline{2}]$ direction (Fig. 1e). The dividing boundaries are

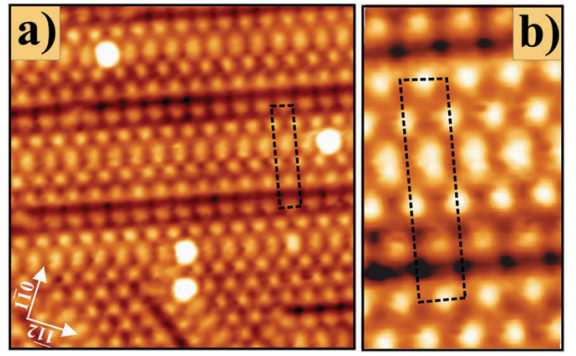

Fig. 3 Close-up STM images of a $(2 \times 2)$ derived $\mathrm{Cu}-\mathrm{O}$ monolayer film arranged in [11̄0]-oriented stripes, (a) $10 \times 10 \mathrm{~nm}^{2}$ and (b) $5 \times 3 \mathrm{~nm}^{2}$.

of zig-zag type and made of short, $\mathrm{Au}[1 \overline{1} 0]$-oriented sections. Moreover, the registry of $(2 \times 2)$ maxima switches between integer and half-order positions when crossing a line defect, a typical behaviour of antiphase domain boundaries. At optimum annealing, the $(2 \times 2)$ domains stretch over $200 \AA$ in the long direction, while their width remains limited to $35 \AA$.

The final high-temperature phase develops upon vacuum annealing to $700 \mathrm{~K}$, when the elongated $(2 \times 2)$ domains transform into homogenous stripes running along equivalent $\mathrm{Au}[1 \overline{1} 0]$ directions (Fig. 1f). Their inner structure is again governed by hexagonal $(2 \times 2)$ units, while two types of boundaries delimit the stripes (Fig. 3). The first one is formed by a dark, single or double line, the second appears as characteristic succession of elliptical maxima with $5.8 \AA$ spacing. The distance between boundaries of the same type varies from 27.5 to $32.5 \AA$ for narrow and wide stripes, respectively, which corresponds to $5 \frac{1}{2}$ and $6 \frac{1}{2}$ gold unit cells in $[11 \overline{2}]$ direction. The non-integer periodicity demonstrates that always two stripes form one repeat unit with respect to gold, or similarly that neighbouring stripes have an antiphase relationship again. The periodicity along the stripe axis amounts to $5.8 \AA$ A, i.e. two repeat units along $\mathrm{Au}[1 \overline{1} 0]$.

\section{Theoretical results on copper oxide monolayers}

Our first-principle simulations of $\mathrm{Cu}-\mathrm{O}$ films focus on monolayer structures, hence samples annealed to $600 \mathrm{~K}$ and higher. In these limits, we have modelled infinite $\mathrm{CuO}_{x}$ layers and stripes with various compositions and dimensions and analysed their stability, electronic properties and STM signatures.

\subsection{Infinite $\mathrm{Cu}_{3} \mathrm{O}_{2}$ monolayer on $\mathrm{Au}(111)$}

When reducing the thickness of gold-supported $\mathrm{Cu}_{2} \mathrm{O}(111)$ films to the monolayer limit (actually to a single $\mathrm{O}-\mathrm{Cu}_{4}-\mathrm{O}$ trilayer), only the three O-bound $\mathrm{Cu}$ atoms remain thermodynamically stable, while the fourth, chemically unsaturated species is unstable in the whole range of oxygen chemical potentials. Stability of this $\mathrm{Cu}_{\mathrm{Cus}}$ atom requires a minimum thickness of 3-4 monolayers, as discussed in the ESI. $\dagger$ The Au-supported monolayer has thus $\mathrm{Cu}_{3} \mathrm{O}_{2}$ stoichiometry and exhibits a honeycomb structure, in which three-fold coordinated anions are placed alternatively above $\left(\mathrm{O}_{\mathrm{up}}\right)$ and below $\left(\mathrm{O}_{\mathrm{dn}}\right)$ the central plane of two-fold coordinated $\mathrm{Cu}$ ions (Fig. 4). 


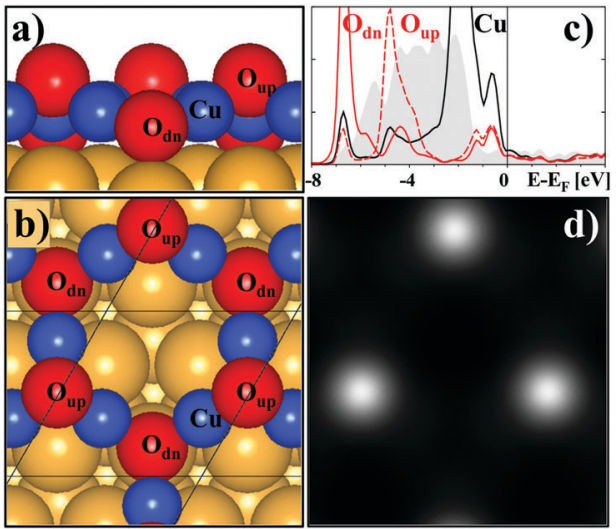

Fig. 4 Au-supported $\mathrm{Cu}_{3} \mathrm{O}_{2}$ monolayer: (a) side and (b) top view of the atomic structure, (c) projected density of states and (d) simulated STM image at positive bias voltage.

In the energetically favoured lattice registry, the cations bind to hollow positions of the $\mathrm{Au}(111)$ surface, while the $\mathrm{O}_{\mathrm{dn}}$ and $\mathrm{O}_{\mathrm{up}}$ species attach to Au-top and hollow sites, respectively. ${ }^{26}$ While the unsupported $\mathrm{Cu}_{3} \mathrm{O}_{2}$ honeycomb structure is perfectly flat, the supported film exhibits a buckling, in which the distance between $\mathrm{O}_{\mathrm{dn}}$ and $\mathrm{Cu}$ planes amounts to $0.4 \AA$ and between $\mathrm{Cu}$ and $\mathrm{O}_{\text {up }}$ planes $0.9 \AA$. An outward relaxation of oxygen in oxide films supported on electronegative metal substrates has already been reported and relates to the electrostatic repulsion between the anions and the negatively charged metal substrate. ${ }^{33}$ Also in the present case, this mechanism is operational since a moderate electron transfer takes place from the $\mathrm{Cu}_{3} \mathrm{O}_{2}$ film towards the gold. However, pronounced electron back-transfer along the short interfacial O-Au bonds $(2.33 \AA)$ considerably reduces the excess charge in the gold to $0.06 e$ per $\mathrm{Cu}_{3} \mathrm{O}_{2}$. Also, inequivalent oxygen adsorption sites and the rigidity of linear $\mathrm{O}-\mathrm{Cu}-\mathrm{O}$ bonds inhibit an outward relaxation of all anions.

The small electron transfer at the metal/oxide interface is insufficient to stabilize an integer oxidation state of the substoichiometric $\mathrm{Cu}$ cations and supported $\mathrm{Cu}_{3} \mathrm{O}_{2}$ films are therefore metallic with a depleted valence-band maximum (Fig. 4c). Simulated STM images for the unoccupied states, calculated by the Tersoff-Haman formalism, ${ }^{34}$ show bright features at the position of the $\mathrm{O}_{\mathrm{up}}$ ions, while the $\mathrm{O}_{\mathrm{dn}}$ and $\mathrm{Cu}$ species do not produce detectable protrusions (Fig. 4d). The contrast is therefore of geometric origin, as the $\mathrm{O}_{\mathrm{up}}$ species are located well above the $\mathrm{Cu}$ layer.

\subsection{Alternative structures in $\mathrm{Cu}-\mathrm{O}$ monolayers on $\mathrm{Au}(111)$}

The honeycomb $\mathrm{Cu}_{3} \mathrm{O}_{2}$ lattice can be seen as network of linear $\mathrm{O}-\mathrm{Cu}-\mathrm{O}$ elements sharing 3 -fold coordinated anions. However, other 2D-periodic arrangements of $\mathrm{O}-\mathrm{Cu}-\mathrm{O}$ elements are conceivable as well, for instance triangular and square networks with 6-fold and 4-fold coordinated anions and $\mathrm{Cu}_{3} \mathrm{O}$ and $\mathrm{Cu}_{2} \mathrm{O}$ stoichiometry, respectively. At the oxygen-lean conditions of the experiment, the calculated stability lies in between the $\mathrm{Cu}_{3} \mathrm{O}_{2}$ honeycomb (for $\Delta \mu_{\mathrm{O}}>-2.0 \mathrm{eV}$ ) and the $\mathrm{Cu}_{2} \mathrm{O}$ square network $\left(\Delta \mu_{\mathrm{O}}<-2.0 \mathrm{eV}\right)$, as indicated in the ESI. $\dagger$ As a consequence, local defects with square structure might be present in the

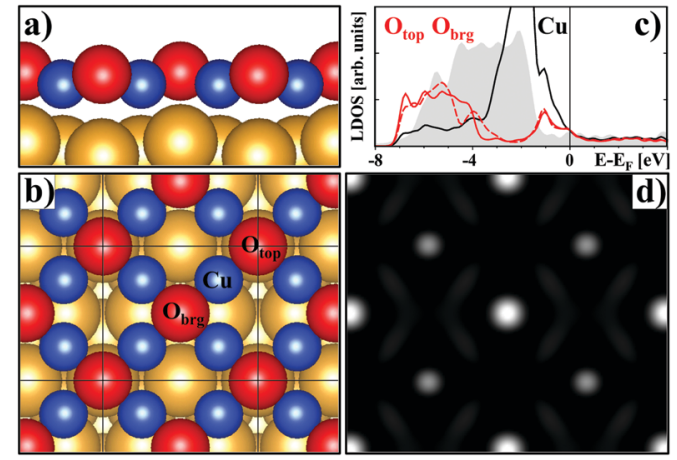

Fig. 5 Au-supported $\mathrm{Cu}_{2} \mathrm{O}$ monolayer: (a) side and (b) top view of the atomic structure, (c) projected density of states and (d) simulated STM image for the unoccupied states.

honeycomb lattice, especially if they enable better match with the gold substrate. On the other hand, the different $\mathrm{O}-\mathrm{Cu}-\mathrm{O}$ angles in hexagonal $\left(120^{\circ}\right)$ and square networks $\left(90^{\circ}\right)$ render a mixing of the two structural elements energetically unfavourable.

The structural and electronic properties of an infinite square monolayer on $\mathrm{Au}(111)$ are summarized in Fig. 5. Although interfacial charge transfer and metal-oxide binding strength largely follow those in the honeycomb layer, the anions in the square lattice show a different relaxation behaviour. Here, the $\mathrm{O}$ ions bound to Au-top and bridge sites relax outwards by 0.4 and $0.2 \AA$ with respect to the $\mathrm{Cu}$ plane. As a result, both types of anions contribute to the STM contrast and produce a dense square lattice in simulated images (Fig. $5 \mathrm{~d}$ ).

\subsection{Finite $\mathrm{Cu}_{3} \mathrm{O}_{2}$ stripes on $\mathrm{Au}(111)$}

To get insight into the domain structure of the hightemperature $\mathrm{Cu}-\mathrm{O}$ films, we have simulated finite honeycomb stripes running along the $\mathrm{Au}[110]$ direction and analysed their composition and stability as a function of edge composition and width. Atomic models for different $\mathrm{Cu}_{3} \mathrm{O}_{2}$ stripe terminations are displayed in Fig. 6. Whereas the edges in models (A) and (D) are Cu-terminated, those in (B) and (E) are delimited by oxygen, and (C) stripes have mixed termination. Only two of these terminations are thermodynamically stable. The $\mathrm{Cu}$-rich (A) edge prevails at oxygen-lean conditions $\left(\Delta \mu_{\mathrm{O}}<-0.9 \mathrm{eV}\right)$, while stripes delimited by two-fold coordinated oxygen ions a)

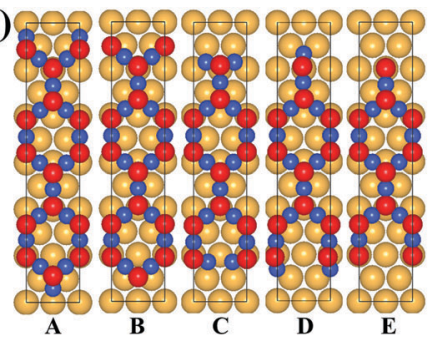

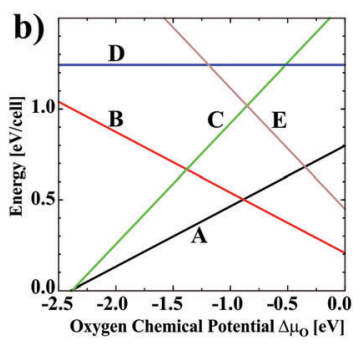

Fig. 6 (a) Structures and (b) formation energies of Au-supported stripes terminated by edges of different stoichiometry. The formation energies are determined with respect to an infinite $\mathrm{Cu}_{3} \mathrm{O}_{2}$ honeycomb monolayer on $\mathrm{Au}(111)$ and a free oxygen molecule. 
a)
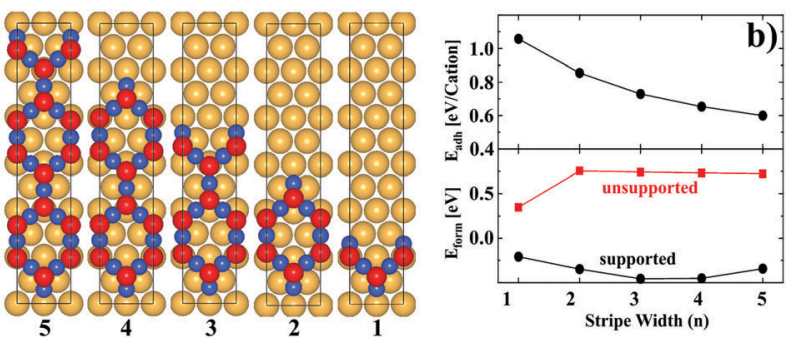

Fig. 7 (a) Structure and (b) adhesion $\left(E_{\text {adh }}\right.$ ) as well as formation energy ( $E_{\text {form }}$ ) of honeycomb stripes with $\mathrm{Cu}_{3 n+1} \mathrm{O}_{2 n}$ stoichiometry and $\mathrm{Cu}$-rich edges (A model) calculated as a function of stripe width $n$. The formation energies are determined with respect to the energy of a supported, infinite $\mathrm{Cu}_{3} \mathrm{O}_{2}$ honeycomb layer and of a single $\mathrm{Cu}$ ad-atom. Corresponding results for unsupported stripes are given as reference.

(B) are favoured in oxygen excess $\left(\Delta \mu_{\mathrm{O}}>-0.9 \mathrm{eV}\right)$. Moreover, since the energetically preferred edges tend to minimize the number of broken bonds, coordination rather than polarity (only edges in model (D) are non-polar) governs the thermodynamic stability. ${ }^{35,36}$ Based on our computational results, we expect the Cu-terminated (A) edges to prevail at the oxygen-lean conditions of the experiment. An important characteristic of this edge type is the strong outward relaxation of the $\mathrm{O}$ anions, producing the distinct triangular pattern observed on both sides of $\mathrm{Au}[110]$-oriented honeycomb stripes (see Fig. 3 and ESI $\dagger$ ).

The structure and energetics of stripes terminated with the preferred Cu-rich (A) edges have been studied also as a function of stripe width, here expressed by the number $n$ in $\mathrm{Cu}_{3 n+1} \mathrm{O}_{2 n}$ repeat units (Fig. 7). As the stripe width increases, a monotonic decrease in adhesion energy per cation $\left(E_{\mathrm{adh}}\right)$ is found, driven by the reduced contribution of under-coordinated edge atoms that interact the strongest with the gold surface. Conversely, the formation energy of supported stripes $\left(E_{\text {form }}\right)$ shows a local minimum for widths $n$ equal to 3-4, while that of unsupported stripes quickly converges to a constant value representative for twice their edge energy (Fig. 7b). Such a substrate-induced minimum in $E_{\text {form }}$ suggests the development of $\mathrm{Cu}_{3} \mathrm{O}_{2}$ stripes with finite widths, stabilized by misfit strain on the $\mathrm{Au}(111)$ surface.

Finally, the symmetric Cu-terminated stripes are always composed of an even number of oxygen rows, and, as discussed above, feature a strong outward relaxation of anions close to the edges. The resulting $\mathrm{O}_{\mathrm{up}}$ configuration at both stripe edges is incompatible with the alternating $\mathrm{O}_{\mathrm{up}} / \mathrm{O}_{\mathrm{dn}}$ relaxation pattern typical for infinite honeycomb layers. Stripes of finite width therefore introduce a structural frustration that mainly impacts the stripe centre (see ESI $\dagger$ ). In the widest stripes considered here $(n=5)$, the structural frustration results in a narrow line defect positioned in the very stripe centre.

\section{Discussion: structure models of copper oxide films}

The final section of our paper aims to rationalize the observed $\mathrm{Cu}-\mathrm{O}$ morphologies on $\mathrm{Au}(111)$, using the DFT calculations performed on the high-temperature $(2 \times 2)$ phases. On this
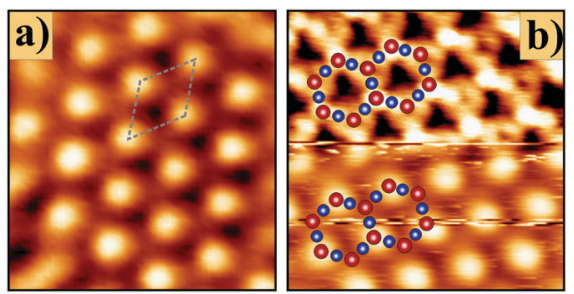

Fig. 8 (a) STM image of the honeycomb $\mathrm{Cu}_{3} \mathrm{O}_{2}$ monolayer taken with a metallic tip $\left(0.5 \mathrm{~V}, 3 \times 3 \mathrm{~nm}^{2}\right)$. A tip change in (b) makes not only the $(2 \times 2)$ lattice of the $\mathrm{O}_{\mathrm{up}}$ ions but both oxygen species visible.

basis, we then develop preliminary models for the low-temperature, multilayer structures that have not been addressed by ab initio calculations due to their complexity. As discussed in section 4.1, the idealized $\mathrm{Cu}_{3} \mathrm{O}_{2}$ monolayer in $(2 \times 2)$ registry with the $\mathrm{Au}(111)$ support is composed of interwoven, six-membered $\mathrm{Cu}-\mathrm{O}$ rings, with the $\mathrm{O}$ ions alternatingly occupying hollow and top sites in the gold surface. The former locate more than $1 \AA$ above their top-bound counterparts and produce the hexagonal $(2 \times 2)$ pattern seen in simulated and experimental STM images (Fig. 4d and 8a). Even better resolved STM data, obtained with $\mathrm{H}_{2} \mathrm{O}$-functionalized tips, shows both the $\mathrm{O}_{\mathrm{up}}$ and $\mathrm{O}_{\mathrm{dn}}$ species of the $\mathrm{Cu}_{3} \mathrm{O}_{2}$ layer (Fig. 8b).

While the $(2 \times 2)$ lattice is common to all high-temperature $\mathrm{Cu}-\mathrm{O}$ films, it is the characteristic domain structure that discriminates the various phases (Fig. 1d-f). The development of finite-sized domains is generally ascribed to misfit strain between oxide layer and metal support, being released in domain boundaries whose density and straightness is affected by the conditions of sample annealing. The highest concentration of line defects is found in $\mathrm{Cu}-\mathrm{O}$ films annealed to $600 \mathrm{~K}$. The respective boundaries form a distinct triangular pattern, across which the atomic registry jumps by one $\mathrm{Au}[1 \overline{1} 0]$-type lattice vector (Fig. 9a and $\mathrm{b}$ ). This increases the distance between adjacent $(2 \times 2)$ maxima from $5.8 \AA$ inside to $7.6 \AA$ across two domains. The extra space is sufficient to add $\mathrm{Cu}$ atoms along the edges in order to realize the thermodynamically preferred Cu-rich (A)-type edge, shown in Fig. 6. Given the isotropic nature of misfit strain and the trifold symmetry of the two lattices, the domains take the triangular shape observed here.

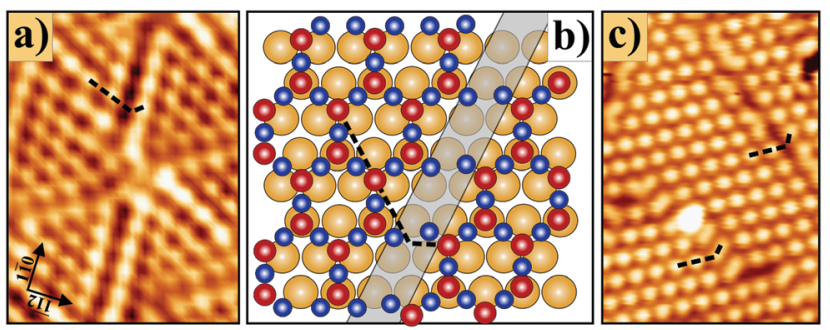

Fig. 9 (a) Close-up STM image of a $(2 \times 2)$ derived $\mathrm{Cu}-\mathrm{O}$ monolayer film with triangular domains. (b) Ball model of a line defect showing the displacement vector deduced from (a). Similar dislocations are found in $(2 \times 2)$ films with elongated domains obtained at $660 \mathrm{~K}$ annealing (c). The STM images are $7 \times 5 \mathrm{~nm}^{2}$ in size. 
The oxide relaxation pattern undergoes a distinct change upon vacuum annealing to $660 \mathrm{~K}$. The initially triangular domains, each one covering about $10 \mathrm{~nm}^{2}$, transform into elongated regions that align with an $\mathrm{Au}[11 \overline{2}]$ direction and stretch over more than $70 \mathrm{~nm}^{2}$. Such an anisotropic reorganization requires the compression of the $\mathrm{Cu}-\mathrm{O}$ lattice along one symmetry axis. The energy costs are balanced by reducing the boundary length by about $30 \%$. The atomic nature of the boundaries, on the other hand, does not change with respect to the triangular pattern discussed before. Again, two $\mathrm{Au}[1 \overline{1} 0]-$ oriented lattice vectors separate adjacent $(2 \times 2)$ maxima inside a domain, while a third vector rotated by $\pm 60^{\circ}$ is needed to reach a protrusion across the line defect. The extra space helps realizing the energetically preferred Cu-termination and releases misfit strain along two $\mathrm{Au}[11 \overline{2}]$ directions, but not along the main domain axis. In this direction, the $\mathrm{Cu}-\mathrm{O}$ honeycomb lattice undergoes a tetragonal distortion to maintain registry with the $\mathrm{Au}(111)$ lattice. The associated activation barrier might explain why the restructuring only occurs at $660 \mathrm{~K}$.

The final reorganization of the honeycomb lattice takes place at $700 \mathrm{~K}$, when the $2 \mathrm{D}$ layer breaks apart into a regular pattern of [110]-oriented stripes (Fig. 3). The stripe width of either 27.5 or $32.5 \AA$ A closely matches the short domain axis revealed in former annealing steps. This suggests that the principles of strain relaxation are unchanged and only the boundaries have straightened up to align perfectly with the $\mathrm{Au}[1 \overline{1} 0]$ direction. A main difference is the occurrence of two boundary types in [110] stripes, a dark one and a bright one made up of elliptical protrusions (Fig. 3). The dark lines are compatible with the type of dislocations discussed before. The bright elliptical protrusions, on the other hand, occupy regular $(2 \times 2)$ positions of the honeycomb lattice, indicating a stoichiometric rather than a structural origin. To explore their nature, three qualitatively different structure models have been considered, all of them based on unit cells of $30 \AA$ length (Fig. 10). Note that the experimental stripe widths of 27.5 or $32.5 \AA$ are incommensurate with the Au support and actual coincidence cells are two times larger, too big for an efficient DFT optimization.

In a first approach, we have modelled a regular $n=4$ honeycomb stripe with Cu-terminated edges (Fig. 10a). The corresponding STM simulation exhibits a triangular $(2 \times 2)$ pattern along the stripe edges due to the $\mathrm{O}_{\mathrm{up}} / \mathrm{O}_{\mathrm{dn}}$ sequence

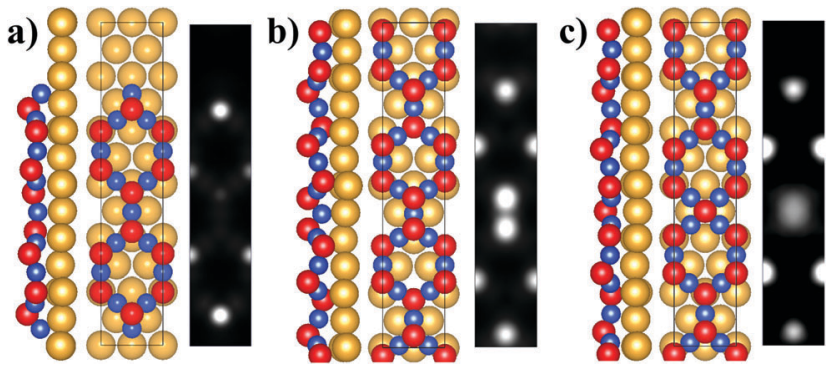

Fig. 10 Structure models of different high-temperature $\mathrm{Cu}-\mathrm{O}$ stripes: (a) finite $n=4$ honeycomb stripe, (b) Moiré pattern in an ideal honeycomb lattice and (c) stoichiometric square defect in the honeycomb layer. discussed before. Neighbouring stripes are separated by dark lines, mimicking the domain boundaries seen in experiment. However, the edge-induced $\mathrm{O}_{\mathrm{dn}} / \mathrm{O}_{\mathrm{dn}}$ structural frustration gives rise to another dark line in the stripe centre, instead of the bright elongated spots found in STM (Fig. 3). Remind that the vertical positions of such frustrated anions might be particularly sensitive to vibrations, soft modes, in-plane strain, and interaction with the STM tip and their experimental contrast might thus be different from the $0 \mathrm{~K}$ Tersoff-Hamann simulation presented here. Moreover, the structural frustration may enhance the local reactivity of the oxide film, which makes these regions prone to adsorption processes, hence to changes of the STM signature.

The second model is based on a continuous and stoichiometric $\mathrm{Cu}_{3} \mathrm{O}_{2}$ honeycomb monolayer, in which the substrateinduced strain is released in a Moiré pattern that extends over the $30 \AA$ of the coincidence cell (Fig. 10b). The registry change between oxide and metal lattices along the Moiré cell produces a frustrated $\mathrm{O}_{\mathrm{dn}} / \mathrm{O}_{\mathrm{dn}}$ row sequence of anions, similar to the one in the centre of $n=4$ stripes (Fig. 10a). The periodicity of the honeycomb lattice requires however a second $\mathrm{O}_{\mathrm{up}} / \mathrm{O}_{\mathrm{up}}$ or $\mathrm{O}_{\mathrm{dn}} / \mathrm{O}_{\mathrm{dn}}$ frustrated sequence in the Moiré cell. While the relative stability of the two defects is sensitive to the in-plain strain, i.e. the unit-cell size, the STM simulation with one $\mathrm{O}_{\mathrm{dn}} / \mathrm{O}_{\mathrm{dn}}$ sequence (appears as dark line) and one $\mathrm{O}_{\mathrm{up}} / \mathrm{O}_{\mathrm{up}}$ sequence (appears as line of bright double spots) closely resembles the experimental pattern (Fig. 10b). Finally, a model based on a continuous $\mathrm{Cu}_{3} \mathrm{O}_{2}$ film with periodically inserted stoichiometry defects is shown in Fig. 10c. The layer may be seen as $\mathrm{Cu}_{13} \mathrm{O}_{8}$ stripes with optimal $n=4$ width, interconnected by lines of square $\mathrm{Cu}_{2} \mathrm{O}$ elements. The thermodynamic possibility of square and hexagonal units coexisting at oxygen-lean conditions has already been demonstrated in section 4.2. A simulated STM pattern of this model contains indeed dark lines due to frustrated $\mathrm{O}_{\mathrm{dn}} / \mathrm{O}_{\mathrm{dn}}$ sequences and bright lines due to the oxygen atoms in the square defects. While the appearance of the square units depends on the $\mathrm{Cu}-\mathrm{O}-\mathrm{Cu}$ bond angles, hence on the overall misfit strain, also this structure shows good match with the experimental [110]-oriented $\mathrm{Cu}-\mathrm{O}$ stripes.

In the final part of our paper, we discuss possible configurations for the low-temperature $\mathrm{Cu}-\mathrm{O}$ phases on $\mathrm{Au}(111)$, as depicted in Fig. 1a and b. None of these structures have been modelled with DFT, although individual structural elements were considered and may now serve as building blocks (see ESI $\dagger$ ). All high-temperature films discussed so far consist of interwoven sixmembered $\mathrm{Cu}-\mathrm{O}$ rings and are of $\mathrm{Cu}_{3} \mathrm{O}_{2}$ stoichiometry. A building block that would support $\mathrm{Cu}_{2} \mathrm{O}$ stoichiometry is a square unit with four $\mathrm{O}$ ions in corner positions and four $\mathrm{Cu}$ ions located at the edges (see Fig. 2a, inset). Such units are $5 \times 5 \AA^{2}$ in size and also present in the $\mathrm{Cu}_{2} \mathrm{O}(100)$ surface. Square structures of similar dimensions can now be identified in the [112] ] stripes formed at $450 \mathrm{~K}$, although their appearance shows certain variations due to changing tip conditions. $\mathrm{A} \mathrm{Cu}_{2} \mathrm{O}(100)$-derived oxide made of square $\mathrm{Cu}-\mathrm{O}$ elements may therefore provide a first model for the $[11 \overline{2}]$ stripe phase, even if the mutual connections between the units are not yet clear. 
A similar approach leads to a tentative structure model for the [110]-oriented stripes formed at $550 \mathrm{~K}$ annealing (Fig. 2c). Here, the differently sized pores on both sides of the stripes are interpreted as $\mathrm{Cu}-\mathrm{O}$ hexagons and $\mathrm{Cu}_{2} \mathrm{O}$ squares. By arranging them in suitable manner, the overall width and the zig-zag lines along the stripes can be reproduced (Fig. 2d). The rectangular 2D pattern that often coexists with the $[1 \overline{1} 0]$ stripes may be explained in similar fashion (Fig. 1c). Here, two $\mathrm{Cu}_{2} \mathrm{O}$ squares, as in Fig. 2a, merge to a rectangular unit of $10 \times 8.5 \AA^{2}$ size by expelling the central $\mathrm{Cu}$ ion.

Two effects are proposed to drive the transition from $[11 \overline{2}]$ to [110]-oriented stripes upon annealing. First, the $\mathrm{Au}(111)$ herringbone reconstruction with its [112]]-aligned row/trough structure gets lifted, which removes a stabilizing factor for $\mathrm{Cu}-\mathrm{O}$ stripes running in the same direction. And second, the oxide stoichiometry continuously changes in the annealing process, as $\mathrm{Cu}$ dissolves in the Au crystal and $\mathrm{O}_{2}$ evaporates to the gas phase. As a result, the thick $\mathrm{Cu}_{2} \mathrm{O}$ films in either [11̄] or [11̄0] stripe configuration transform into a $\mathrm{Cu}_{3} \mathrm{O}_{2}$ honeycomb lattice that is thermodynamically preferred at high temperature. It is interesting to note that the template effect of the $\mathrm{Au}(111)$ is unable to fix the honeycomb $\mathrm{Cu}_{3} \mathrm{O}_{2}$ right from the beginning despite a rather perfect lattice match. Apparently, neither the $\mathrm{Au}-\mathrm{Cu}$ nor $\mathrm{Au}-\mathrm{O}$ bonds are sufficiently strong to imprint the hexagonal symmetry directly onto the growing oxide film.

\section{Conclusions}

Morphology changes in ultrathin $\mathrm{Cu}-\mathrm{O}$ films grown on an $\mathrm{Au}(111)$ support have been studied as a function of temperature with STM and DFT. The low-temperature oxide phases appear as $\mathrm{Au}[11 \overline{2}]$ and $[1 \overline{1} 0]$-oriented stripes and carry distinct elements of the $\mathrm{Cu}_{2} \mathrm{O}(100)$ and (111) bulk termination, respectively. With increasing temperature, the oxide thins down to a $\mathrm{Cu}_{3} \mathrm{O}_{2}$ monolayer with honeycomb structure. $\mathrm{Cu}_{2} \mathrm{O}$ square elements occur as stoichiometric defects in the layer at low oxygen chemical potential. The honeycomb lattice is delimited by temperature-specific domain boundaries, made of $\mathrm{Cu}$-terminated and $\mathrm{Au}[1 \overline{1} 0]$-oriented edges of different length and straightness. The diversity of copper-oxide films observed here is the result of the high structural flexibility of the $\mathrm{Cu}-\mathrm{O}-\mathrm{Cu}$ bonds and a rather weak template effect of the $\mathrm{Au}$ support. Preparation of bulk-derived $\mathrm{Cu}_{2} \mathrm{O}$ structures may be easier by replacing the Au support with a more rigid substrate of hexagonal symmetry, such as $\mathrm{Pt}(111)$.

\section{Conflicts of interest}

There are no conflicts to declare.

\section{Acknowledgements}

C. M. and N. N. are grateful for financial support via the DFG grant 'Towards atomic-scale understanding of ideal, defective and doped cuprous oxide surfaces and interfaces'. J. G. and C. N. gratefully acknowledge the generous allocation of computing time at IDRIS under project no. 100170.

\section{References}

1 Q. Fu and T. Wagner, Surf. Sci. Rep., 2007, 62, 431-498.

2 N. Nilius, Surf. Sci. Rep., 2009, 64, 595-659.

3 H.-J. Freund, J. Am. Chem. Soc., 2009, 138, 8985-8996.

4 J. Wollschläger, D. Erdös, H. Goldbach, R. Höpken and K. M. Schröder, Thin Solid Films, 2001, 400, 1-8.

5 X. Shao, P. Myrach, N. Nilius and H.-J. Freund, J. Phys. Chem. C, 2011, 115, 8784-8789.

6 E. Lundgren, G. Kresse, C. Klein, M. Borg, J. N. Andersen, M. De Santis, Y. Gauthier, C. Konvicka, M. Schmid and P. Varga, Phys. Rev. Lett., 2002, 88, 246103.

7 M. Schmid, M. Shishkin, G. Kresse, E. Napetschnig, P. Varga, M. Kulawik, N. Nilius, H.-P. Rust and H.-J. Freund, Phys. Rev. Lett., 2006, 97, 046101.

8 J. Weissenrieder, S. Kaya, J. L. Lu, H. Gao, S. Shaikhutdinov, H.-J. Freund, M. Sierka, T. K. Todorova and J. Sauer, Phys. Rev. Lett., 2005, 95, 076103.

9 L. Giordano, G. Pacchioni, C. Noguera and J. Goniakowski, Top. Catal., 2013, 56, 1074-1081.

10 Thin Film Growth, ed. Z. Cao, Woodhead Publishing, Cambridge, 2011.

11 L. Giordano and G. Pacchioni, Acc. Chem. Res., 2011, 44, 1244-1252.

12 S. Surnev, G. Kresse, M. Sock, M. G. Ramsey and F. P. Netzer, Surf. Sci., 2001, 495, 91-106.

13 F. Allegretti, C. Franchini, V. Bayer, M. Leitner, G. Parteder, B. Xu, A. Fleming, M. G. Ramsey, R. Podloucky, S. Surnev and F. P. Netzer, Phys. Rev. B: Condens. Matter Mater. Phys., 2007, 75, 1-8.

14 K. Heinz and L. Hammer, J. Phys.: Condens. Matter, 2013, 25, 173001.

15 C. Wu, M. R. Castell, J. Goniakowski and C. Noguera, Phys. Rev. B: Condens. Matter Mater. Phys., 2015, 91, 155424.

16 S. Benedetti, H. M. Benia, N. Nilius, S. Valeri and H.-J. Freund, Chem. Phys. Lett., 2006, 430, 330-335.

17 G. Renaud, Surf. Sci. Rep., 1998, 32, 1-90.

18 S. Benedetti, F. Stavale, S. Valeri, C. Noguera, H.-J. Freund, J. Goniakowski and N. Nilius, Adv. Funct. Mater., 2013, 23, 75-80.

19 B. K. Meyer, A. Polity, D. Reppin, M. Becker, P. Hering, P. J. Klar, T. Sander, C. Reindl, J. Benz, M. Eickhoff, C. Heiliger, M. Heinemann, J. Bläsing, A. Krost, S. Shokovets, C. Müller and C. Ronning, Phys. Status Solidi, 2012, 249, 1487-1509.

20 A. Akgul, G. Akgul, N. Yildirim, H. E. Unalan and R. Turan, Mater. Chem. Phys., 2014, 147, 987-995.

21 A. Soon, M. Todorova, B. Delley and C. Stampfl, Surf. Sci., 2007, 601, 5809-5813.

22 P. Poizot, C.-J. Hung, M. P. Nikiforov, E. W. Bohannan and J. A. Switzer, Electrochem. Solid-State Lett., 2003, 6, 21-25.

23 V. Maurice, L. H. Klein, H. Strehblow and P. Marcus, J. Electrochem. Soc., 2003, 458, 316-324.

24 F. Yang, Y. Choi, P. Liu, D. Stacchiola, J. Hrbek and A. Rodriguez, J. Am. Chem. Soc., 2011, 133, 11474-11477. 
25 F. Jensen, F. Besenbacher and I. Stensgaard, Surf. Sci., 1992, 269-270, 400-404.

26 T. Lee, Y. Lee, K. Kang and A. Soon, Phys. Chem. Chem. Phys., 2016, 18, 7349-7358.

27 T. Lee, Y. Lee, S. Piccinin and A. Soon, J. Phys. Chem. C, 2017, 121, 2228-2233.

28 H. Sträter, H. Fedderwitz, B. Gross and N. Nilius, J. Phys. Chem. C, 2015, 119, 5975-5981.

29 N. Nilius, H. Fedderwitz, B. Groß, J. Goniakowski and C. Noguera, Phys. Chem. Chem. Phys., 2016, 18, 6729-6733.

30 J. P. Perdew and Y. Wang, Phys. Rev. B: Condens. Matter Mater. Phys., 1992, 45, 13244-13249; J. Heyd, G. E. Scuseria and M. Ernzerhof, J. Chem. Phys., 2003, 118, 8207-8215.
31 G. Kresse and J. Hafner, Phys. Rev. B: Condens. Matter Mater. Phys., 1993, 47, R558-561.

32 P. E. Blöchl, Phys. Rev. B: Condens. Matter Mater. Phys., 1994, 50, 17953-17979; G. Kresse and J. Joubert, Phys. Rev. B: Condens. Matter Mater. Phys., 1999, 59, 1758-1775.

33 J. Goniakowski and C. Noguera, Phys. Rev. B: Condens. Matter Mater. Phys., 2009, 79, 155433.

34 J. Tersoff and D. R. Hamann, Phys. Rev. B: Condens. Matter Mater. Phys., 1985, 31, 805-813.

35 J. Goniakowski, L. Giordano and C. Noguera, Phys. Rev. B: Condens. Matter Mater. Phys., 2013, 87, 035405.

36 C. Noguera and J. Goniakowski, Chem. Rev., 2013, 113, 4073-4105. 